\title{
SEVENTH ANNUAL MEETING
}

\author{
The European Society for Paediatric \\ Haematology and Immunology
}

Oslo, Norway, June 11-13, 1979

1 THE NORML BLOOD PLATELET AND ITS FUNCTION. II. Stormorken, Institute of Thrombosis Research, National Hospital, Univ. of Oslo, Norvay.

Recent research both on the morphological and biochemical level has greatly advanced our knowledge about the platelet and its interaction with the vessel wall and plasmatic factors. The platelet membrane makes platelets unique in their properties to adhere to other surfaces (adlesion) and to each other (aggregation), the main basis for their functional task: to prevent and to stop bleeding. This basic function is coverned by vessel wall factors (eg. collagen) representinf the initial stimulus, by plasmatic factors such as von Villebrand factor and fibrinogen, by platelet nembrane receptors, of which some are identified, and of platelet membrane phospholipids providing the arachidonic acid necessary for thromboxane synthesis and further by compounds contained in the platelet cytosol (cyclooxygenase, thromboxane synthetase and the cyclic AMP system), and in the eranules (eg. ADP), which together are necessary for the release reaction and thus for providing the physiological aggregating stimulus, ADP. The release process can also be initated by other biological compounds including thrombin, thus linking coagulation and platelet function.

2 DENONSTRATION OF PLATELET ANTIBODIES IN IEG FRACTION OF CHILDREN WITH ITP. Ozsoylu, S.. Ozturk, M., Làleil, Y.., Section of lienatology, Department of Pediatrics, Hacettepe University Faculty of Medicine, Ankara, 'Turkey.

Decreased platelet survival in remission as well as in relapse in children with ITP was shown by us. Antiplatelet in the sera of these children were also shown by us by using opsonophagocytic test of Handing and stosse1.

In this study, IGG, IGM and $I_{g A}$ fractions of the sera of thesc patients were separated by colum chromatography and the platelet antibodies were looked for in these fractions by the above method. Although $I_{g G}$ and whole serum showed similar opsonophagocytic activity, it was not shown neither in $I_{g A}$ nor $I_{g N}$ fractions. This activity in I fG fraction disappeared following breaks of its disulphid bonds.

Following absorption with erythrocytes, lymphocytes and platelets, the specificity of the antibodies to platclets are indicated.
3 A MICRO-NETHOD FOR DETECTION OF THROMBOCYTE 3 ANTIBODIES. O.J. Berch, M.S. Beck, E. Thorsby, B.G. Solheim, Tissue 'Typing Laboratory, Rikshospitalet, The National Hospita1, Oslo 1, Norway A micro-method using FITC and ${ }^{125} \mathrm{~T}$-labelled protein $A$ for detection of auto and alloantibodies to human thrombocytes will be presented. The isotope method is based on the use of microtiter plates with 96 wells and Flow Supernatant harvester which permits large scale testing of cell-serum combinations.

Clinical applications of the test for detection of in vivo and in vitro sensitization of platelets will be demonstrated together with casc reports.
4 VINCRISTINE LOADED PLATELETS IN TIE TREATMINNT OF IDIOPATIIC TIIRONBOCY'TOPENIC PURPURA ( ITP). G. Schaison, J.L. Harousseau, G. Tobelem, A. Bussel, liopital St-Louis, Paris, France.

Chronic ITP is the most common autoimune disorder in childlood. Splenectomy is prohibided before 5 years old and after is successfull in only $70 \%$ of the cases With corticosteroids some chronic ITP soem to respond but lonf term treatment leads to undesirable side cffect. Use of immunosuppressive arents is open to criti cism in cililditood.

Y.S. Ahn has reported treatment of refractory ITP in adults with Vinblastin loaded platelets with 6 complete remissions, 3 partial remissions and 2 failures. It is demonstrated that Vinca is concentrated by the platelets. The complex is rapidly cleared and incested by macroplares leading to their destruction.

10 children from 2 to 15 years old wero treated in our department with Vincristin loaded platelets. All. had chronic ITP lastine from 1 to 12 years. Steroid had given good transitory results in 4 cascs. 4 cases had been previously splenectomised with failure. There were 1 food result ald 3 partial transitory remissions

Among 15 adults we have 2 good results.

The discrepancy between Alan's ancl our results is dis. cussed according to the total amount of vinca alcaloid incubated and the number of platelets infused. 